\title{
Conventional and newer antihypertensive drugs had similar efficacy in elderly people with hypertension
}

Hansson L, Lindholm LH, Ekbom T, et al, for the STOP-Hypertension-2 study group. Randomised trial of old and new antihypertensive drugs in elderly patients: cardiovascular mortality and morbidity the Swedish Trial in Old Patients with Hypertension-2 study. Lancet 1999 Nov 20;354:1751-6.

QUESTION: In elderly people with hypertension, are newer antihypertensive drugs as effective as conventional antihypertensive drugs for reducing cardiovascular events?

\section{Design}

Randomised \{allocation concealed*\}†, blinded (outcome assessors),* controlled trial with 4 year follow up.

\section{Setting}

312 health centres in Sweden.

\section{Patients}

6614 patients who were 70 to 84 years of age (mean age $76 \mathrm{y}, 67 \%$ women) and had hypertension (defined as systolic blood pressure $\geqslant 180 \mathrm{~mm} \mathrm{Hg}$ or diastolic blood pressure $\geqslant 105 \mathrm{~mm} \mathrm{Hg}$ or both). Follow up was $100 \%$.

\section{Intervention}

Patients were allocated to 1 of 3 groups: conventional antihypertensive drugs (atenolol, $50 \mathrm{mg} / \mathrm{d}$; metoprolol, $100 \mathrm{mg} / \mathrm{d}$; pindolol, $5 \mathrm{mg} / \mathrm{d}$; or fixed ratio hydrochlorothiazide, $25 \mathrm{mg} / \mathrm{d}$, and amiloride, $2.5 \mathrm{mg} / \mathrm{d})(\mathrm{n}=2213)$; angiotensin converting enzyme (ACE) inhibitors (enalapril, $10 \mathrm{mg} / \mathrm{d}$, or lisinopril, $10 \mathrm{mg} / \mathrm{d})(\mathrm{n}=2205)$; or calcium antagonists (felodipine, $2.5 \mathrm{mg} / \mathrm{d}$, or isradipine, $2.5 \mathrm{mg} / \mathrm{d})(\mathrm{n}=2196)$.

\section{Main outcome measures}

Cardiovascular mortality. Secondary outcome measures included the combined outcome of fatal and non-fatal stroke, fatal and non-fatal myocardial infarction (MI), and other cardiovascular mortality.

\section{Main results}

Analysis was by intention to treat. The proportion of patients still receiving their randomised treatment at the last visit was $62 \%$ for the conventional drug group, $61 \%$ for the ACE inhibitor group, and 66\% for the calcium antagonist group. Groups did not differ for cardiovascular mortality or the combined outcome of stroke, MI, and cardiovascular death. When results for newer drugs (calcium antagonists and ACE inhibitors) were combined, no differences were seen between newer and standard antihypertensive drugs for cardiovascular events (table). Results were similar after adjustment for age, sex, presence of diabetes, diastolic blood pressure, and smoking.

\section{Conclusion}

In elderly people with hypertension, newer antihypertensive drugs had similar efficacy to conventional antihypertensive drugs for reducing cardiovascular events.

*See glossary.

$\dagger$ Information provided by author.

Newer antihypertensive drugs (ACE inhibitors and calcium antagonists) $v$ conventional antihypertensive drugs in elderly people with hypertension

\begin{tabular}{|c|c|c|c|c|}
\hline Outcomes at $4 \mathrm{y}$ & Newer drugs & $\begin{array}{l}\text { Conventional } \\
\text { drugs }\end{array}$ & RRR $(95 \% \mathrm{Cl})$ & NNT (Cl) \\
\hline Cardiovascular death & $10 \%$ & $10 \%$ & $0 \%(-16$ to 14$)$ & Not significant \\
\hline Combined outcome & $20 \%$ & $21 \%$ & $3 \%(-7$ to 12$)$ & Not significant \\
\hline
\end{tabular}

\section{COMMENTARY}

The study by Hansson and colleagues confirms the similar efficacy of a wide range of antihypertensive drugs in reducing the risk for stroke, MI, or cardiovascular mortality in a large population of older patients. The patient population was similar to older patients seen in many practices, although we can infer from the Scandinavian setting of the study that few participants were of African descent. The specific choice of a drug in each category was not randomised, nor were the choices specified in the analysis. $46 \%$ of patients required $\geqslant 1$ drug for blood pressure control.

Subgroup analysis showed some interesting results, with ACE inhibitors being superior to calcium antagonists in reducing the risk for congestive heart failure and MI. With $>40$ subgroup comparisons, these results must be interpreted cautiously, but these findings do fit our understanding of the efficacy of ACE inhibitors in congestive heart failure. The Captopril Prevention Project (a trial comparing captopril with conventional therapy in patients with hypertension) suggested that captopril was less protective against stroke than was treatment with diuretics or $\beta$ blockers or both. ${ }^{1}$ The current study reassuringly finds no differences in stroke incidence among the treatment groups.

What should physicians do with this information? First, they can be reassured that the older, generic, and usually unadvertised drugs (thiazides and $\beta$ blockers) remain effective and should remain first line treatment of older patients with hypertension. Second, in those patients with proven or suspected left ventricular dysfunction, ACE inhibitors may have some advantage over calcium channel blockers in preventing congestive heart failure.

David L Bronson, MD Cleveland Clinic Foundation Cleveland, Ohio, USA

1 Hansson L, Lindholm LH, Niskanen L, et al. Effect of angiotensin-converting-enzyme inhibition compared with conventional therapy on cardiovascular morbidity and mortality in hypertension: the Captopril Prevention Project (CAPPP) randomised trial. Lancet 1999;353:611-6.
Sources of funding: Astra; Merck Sharp and Dohme; Sandoz; Zeneca.

For correspondence: Professor L Hansson, Department of Public Health and Social Sciences, University of Uppsala, PO Box 609 75125 Uppsala, Sweden. Fax +4618 177973. 